\title{
Effectiveness of Nurse-Driven Discharge Teaching Using Mobile Application for Home-Based Health Care Practices among Postoperative Neurosurgical Patients or Caregivers in a Tertiary Care Hospital, New Delhi: A Randomized Control Study
}

\author{
Metilda C.J. ${ }^{1} \quad$ Kamlesh K. Sharma ${ }^{2} \quad$ Aditi P. Sinha ${ }^{2}$ \\ ${ }^{1}$ Department of Neuroscience Nursing, All India Institute of Medical \\ Sciences, New Delhi, India \\ ${ }^{2}$ College of Nursing, All India Institute of Medical Sciences, \\ New Delhi, India \\ ${ }^{3}$ Department of Neurosurgery, All India Institute of Medical \\ Sciences, New Delhi, India
}

\author{
Deepak Agrawal ${ }^{3}$
}

\begin{abstract}
Address for correspondence Metilda C.J., Department of Neuroscience Nursing, All India Institute of Medical Sciences, New Delhi 110029, Delhi, India (e-mail: metildajose@gmail.com).
\end{abstract}

\begin{abstract}
Keywords

- lifestyle practices

- medication compliance

- mobile app-based discharge

- nurse-driven discharge teaching

- postoperative neurosurgery patient

Introduction Considering the increased access to mobile use even in the remote areas, it may be feasible to utilize mobile application (App)-based education among neurosurgical patients and caregivers for home-based care.

Objective This study was aimed to assess the effectiveness of nurse-driven discharge teaching using mobile App for home-based health care practices in terms of discharge advice compliances, revisits, and satisfaction among postoperative neurosurgical patients. Materials and Methods This randomized control trial was conducted among 100 (50 in each arm) postoperative neurosurgical patients admitted to Neurosurgery department, All India Institute of Medical Sciences (AIIMS), New Delhi. The experimental group received mobile App-based discharge teaching additional to the routine paper-based discharge teaching received by the control group. Data were collected at baseline, during first (within 30th day) and second (within 60th day) routine follow-up visits using adherence to refills and medications scale (ARMS) questionnaire (medication compliance), self-developed structured questionnaires (lifestyle practices like tracheostomy tube (TT) catheter care, exercises and diet changes, revisits, and satisfaction) and computerized log record from App. Data were analyzed using descriptive and inferential statistics. Results The demographic and clinical profiles of both groups were comparable. There was no statistically significant difference in medication compliance between the experimental group and control group $(p=0.35$ and 0.53$)$ in first and second posttests, respectively. The level of confidence to perform lifestyle practices was high among experimental group. The subgroup analysis showed that patients in experimental arm were more compliant to medications as compared with control group $(p=0.001)$.
\end{abstract}

published online

March 15, 2021
DOI https://doi.org/

$10.1055 / \mathrm{s}-0041-1724143$ ISSN 0973-0508.
C2021. Neurotrauma Society of India.
This is an open access article published by Thieme under the terms of the Creative
Commons Attribution-NonDerivative-NonCommercial-License, permitting copying
and reproduction so long as the original work is given appropriate credit. Contents
may not be used for commercial purposes, or adapted, remixed, transformed or
built upon. (https://creativecommons.org/licenses/by-nc-nd/4.0/).
Thieme Medical and Scientific Publishers Pvt. Ltd. A-12, 2nd Floor,
Sector 2, Noida-201301 UP, India 
Both the groups were comparable in terms of revisits $(p=0.26)$. However, the overall satisfaction of experimental group was reported to be highly using mobile App based teaching than control group with routine paper-based discharge teaching $(p=0.001)$.

Conclusion Nurse-driven discharge teaching using mobile App is an effective method for neurosurgical patients to adhere to home-based discharge teachings. Use of technology like mobile Apps in vernacular language can bridge the gap for improving home-based care and follow-up among patients in resource constrained settings.

\section{Introduction}

Neurosurgical disorders can lead to severe disability and life-long dependency in the life of a patient. The management of neurological patients aims to reduce their disability and adapt themselves within society. In absence of formal rehabilitative facilities in India, patients must depend on home-based support for rehab and further management. Compliance to the discharge advices given by the doctors or nurses at the time of discharge is important for effective home-based care of these patients. ${ }^{1}$

Mobile technology offers a stupendous opportunity for developing countries, for example, India, for advances in health care delivery system by effectively utilizing scarce resources. As recommended by Felbaum et $\mathrm{al}^{2}{ }^{2}$ it is important to evaluate the utility of smart phone-based applications (Apps) for home-based care which can help in improving the compliance to discharge instructions, as well as a monitored medical care, for the patients in remote areas.

The aim of the study was to assess the effectiveness of nurse-driven discharge teaching using mobile app for home-based health care practices in terms of discharge compliances, revisits, and satisfaction among postoperative neurosurgical patients or caregivers.

\section{Materials and Methods}

A randomized control study was performed from August to December 2019 in neurosurgery department, All India Institute of Medical Sciences (AIIMS), New Delhi. The fresh postoperative patients discharged within 15 days were conveniently selected according to inclusion criteria to the experimental and control group. From 124 eligible participants for the study, 100 participants were enrolled and allotted randomly to experimental (app group) and control group (non-app group; -Fig. 1) The caregivers were enrolled if patients were dependent due to neurological deficits to perform activity of daily living (ADL). Accordingly, a subgrouping was done between the patients and caregivers in both control and experiment group. Ethical permission was obtained from Institute Ethics Committee, AIIMS, New Delhi, and the study was registered in Clinical trials registry of India (CTRI/2019/10/021498).

A self-developed, structured, close-ended questionnaire was used to assess the baseline data, data of lifestyle modifications, and morbidity assessment and level of satisfaction. Adherence to refills and medications scale (ARMS) questionnaire was used for assessing the Medication compliance. Validity and reliability of the tools were done. Experimental group was given the mobile app (Aimeo)-based discharge teaching and routine paper-based discharge teaching, whereas the control group received the routine paperbased discharge. Posttest assessment was done at two time points (within 30 and 60 days of discharge) during routine follow-up visits in outpatient department using the structured questionnaires. Data were collected by the principal investigator and no blinding was done.

\section{Intervention}

The experimental group were provided the mobile appbased discharge teaching before discharge. Two sessions (10 minutes each) of training were held for handholding and usage of Aimeo app installed in the patients smart phone using the individualized user ID. The individualized discharge summary was embedded into the mobile app with educational videos in it. The patient or caregiver was encouraged to update the data in the mobile app as per their discharge advice and reminder SMS were sent to the patients for discharge compliance. Moreover, patients were able to contact the hospital for any medical query or upload their queries as pictures, documents, and voice messages through the app. These features of the Aimeo app ( $\mathbf{- F i g . ~ 2 ) ~ c o u l d ~ h e l p ~}$ the medical personnel in the hospital to monitor the patient remotely. A computerized data record of the updating the data was retrieved from the backend of Aimeo app.

\section{“Aimeo" Mobile App}

"Aimeo" is a mobile-based-app for android and iOS platforms and is freely available in Google Play and Appstore developed by HealthCius Services Pvt. Ltd. It is available in both English and Hindi languages. It helps the patients and caregivers to understand their treatment after discharge and follow it in a structured manner. Patient's or caregivers update the vitals, adherence to discharge advice the app which is shared with the nurse and treating doctor, so that remote patient management is possible. Patients can upload their queries as JPG, PDF, videos, or chat in the mobile app. The call is sent to the patient from call center regarding the query and if medical clarification needed the call is connected to the nurse or doctor resolves the queries of patient or caregivers, thereby managing the patients remotely. 


\section{Data Analysis}

Data were coded and summarized in the master data sheet in Microsoft excel. Statistical package STATA 14.2 version was used to analyze the data using descriptive and inferential statistics. The demographics, lifestyle changes, revisits, and satisfaction of the participants were compared using Chi-square and Fishers' exact tests. Independent $t$-test (two

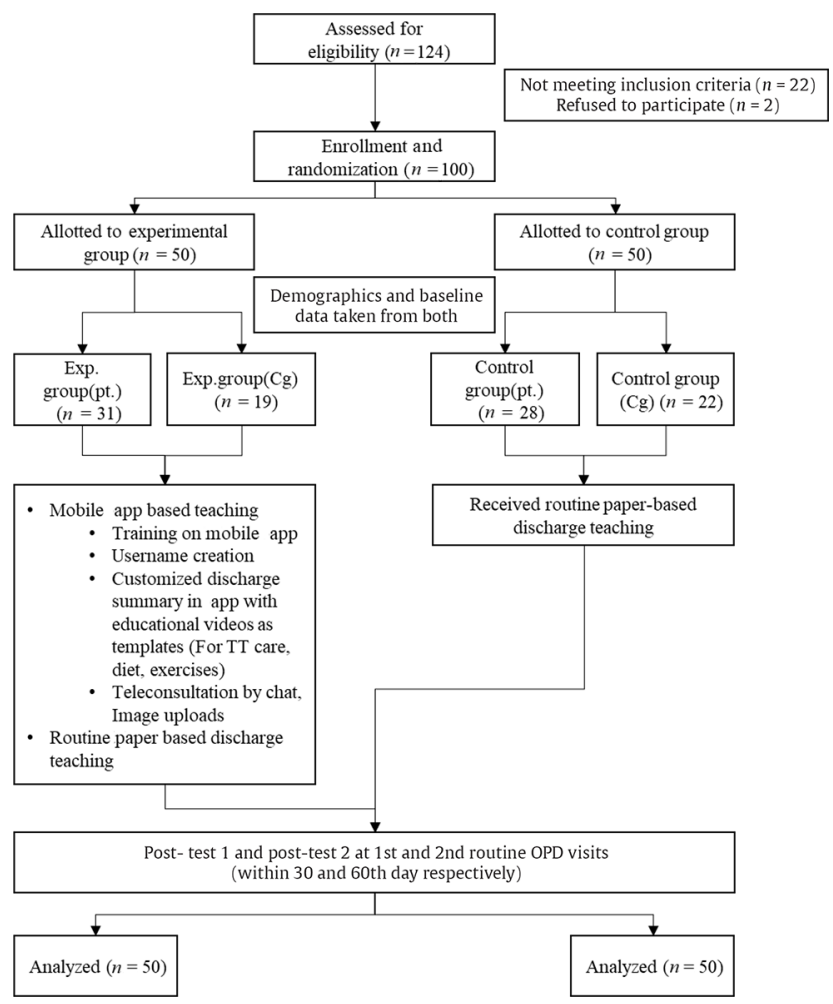

Fig. 1 Consort diagram.

*Experiment group is the group provided with Mobile App based discharge teaching and routine paper based discharge teaching (app group). Control group is the group with routine paper based discharge teaching (Non-app group). sample $t$-test) was used to compare the mean score of medication adherence and age of the study subjects. The level of significance was taken as $p<0.05$.

\section{Results}

\section{Demographics}

The demographic characteristics of the participants are summarized in - Table 1. Demographics of both the group were comparable except for the comorbidities $(p=0.015)$. The comorbidities had no association ( $p=0.26$ ) with incidence of complications (odds ratio [OR (95\% confidence interval $[\mathrm{CI}])=0.59(0.22-1.46)]$ )

\section{Medication Compliance}

The compliance score from ARMS questionnaire were compared among control and experimental group. The score ranged from 12 to 34 (lower score meant better compliance). The control and experimental group showed no significant difference ( $p=0.16$ and 0.26 ) in the scores in posttests 1 and 2 (-Table 2), respectively.

But the subgroup analysis (- Table 3 ) showed that the patient reported medication compliance was better in the experimental group as compared with the control group. There was no significant difference among caregiver of experimental and control group.

\section{Lifestyle Practices}

Level of confidence to perform tracheostomy tube suctioning were compared among 23 patients who were having tracheostomy tube in the control and experimental group. It showed that the experimental group had "moderate-to-high" level of confidence to perform tracheostomy suctioning than control group ( $p=0.03$ and 0.05 ) in posttests 1 and 2 , respectively.

The confidence to perform range of motion (ROM) exercises were higher in experiment group when compared with control group in the second visit $(p=0.013)$. And the patient subgroup reported to have a higher level of confidence to

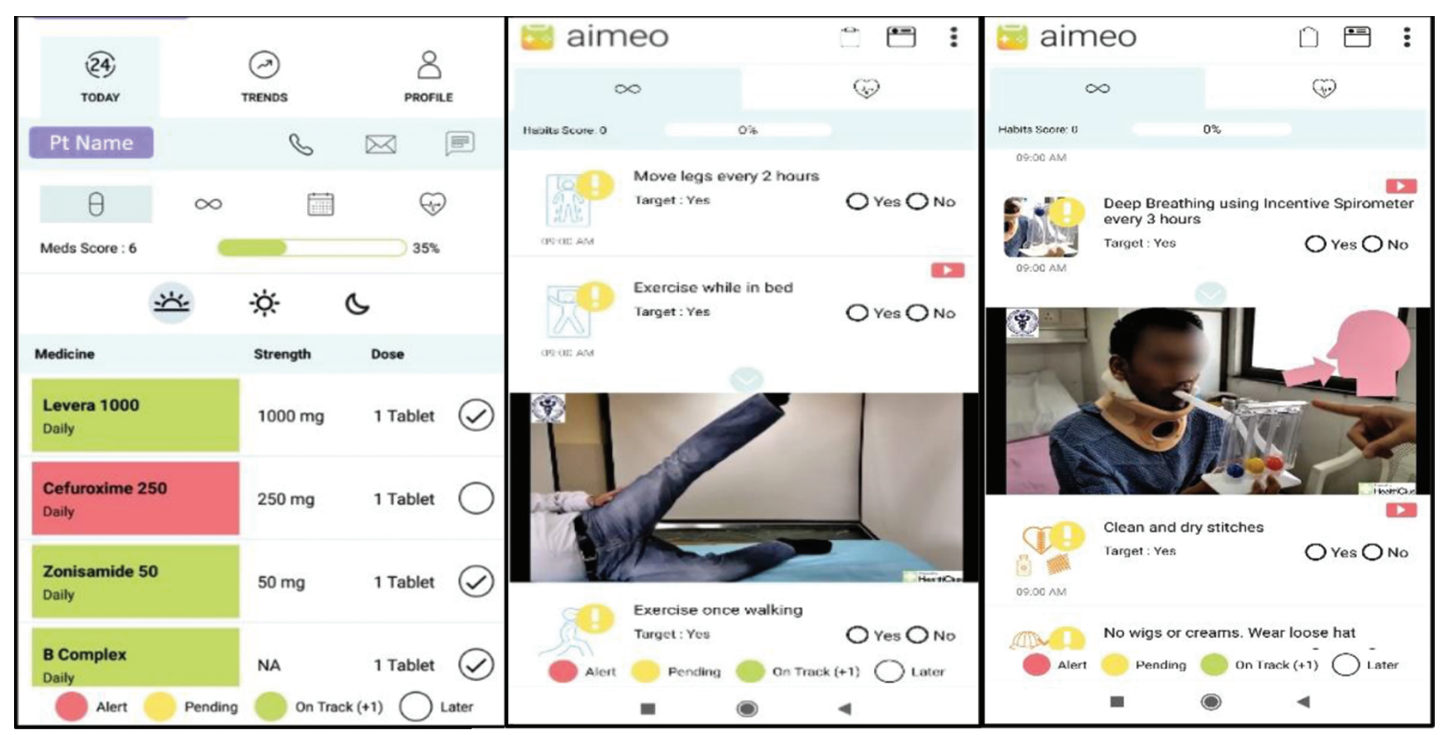

Fig. 2 Templates of homecare practices in "Aimeo" mobile application. 
Table 1 Demographic characteristics of the study patients $(n=100)$

\begin{tabular}{|c|c|c|c|c|}
\hline \multicolumn{2}{|l|}{ Variables } & \multicolumn{2}{|l|}{ Study groups } & \multirow{3}{*}{$\begin{array}{l}p \text {-Value }{ }^{d} \\
0.308\end{array}$} \\
\hline & & \multirow{2}{*}{$\begin{array}{l}\begin{array}{l}\text { Control } \\
\text { frequency (\%) }\end{array} \\
40.40 \pm 15.8^{\mathrm{e}} \\
\end{array}$} & \multirow{2}{*}{$\begin{array}{l}\begin{array}{l}\text { Experimental } \\
\text { frequency (\%) }\end{array} \\
40.44 \pm 14.7^{\mathrm{e}}\end{array}$} & \\
\hline Age $(y)^{a}$ & Mean + SD & & & \\
\hline \multirow[t]{2}{*}{$\operatorname{Sex}^{\mathrm{b}}$} & Male & $31(62)$ & $30(60)$ & \multirow[t]{2}{*}{0.838} \\
\hline & Female & $19(38)$ & $20(40)$ & \\
\hline \multirow[t]{5}{*}{ Education $^{c}$} & Illiterate & $1(2)$ & 0 & \multirow[t]{5}{*}{0.344} \\
\hline & Elementary & $15(30)$ & $22(44)$ & \\
\hline & High school & $15(30)$ & $14(28)$ & \\
\hline & Graduate & $19(38)$ & $13(26)$ & \\
\hline & Postgraduate and above & 0 & $1(2)$ & \\
\hline \multirow[t]{2}{*}{ Area of living ${ }^{b}$} & Rural & $33(66)$ & $38(76)$ & \multirow[t]{2}{*}{0.378} \\
\hline & Urban & $17(34)$ & $12(24)$ & \\
\hline
\end{tabular}

Abbreviation: SD, standard deviation.

aTwo-sample independent $t$-test.

${ }^{\mathrm{b}}$ Chi-square test.

'Fisher's exact test.

${ }^{\mathrm{d}} p<0.05$.

eMean \pm SD.

Table 2 Comparison of adherence to refills and medication scale (ARMS) score among the study patients $(n=100)$

\begin{tabular}{|c|c|c|c|c|c|c|}
\hline \multirow[t]{2}{*}{ Patients $^{\mathrm{b}}$} & \multicolumn{3}{|l|}{ Posttest 1} & \multicolumn{3}{|l|}{ Posttest 2} \\
\hline & Mean \pm SD & $95 \% \mathrm{Cl}$ & $p$-Value ${ }^{a}$ & Mean \pm SD & $95 \% \mathrm{Cl}$ & $p$-Value ${ }^{a}$ \\
\hline Control $(n=50)$ & $21.5 \pm 5.1$ & $20.1-22.9$ & \multirow[t]{2}{*}{0.16} & $23.01 \pm 4.9$ & $21.7-24.4$ & \multirow[t]{2}{*}{0.26} \\
\hline Experimental $(n=50)$ & $20.1 \pm 4.9$ & $18.7-21.5$ & & $22.0 \pm 4.1$ & 20.9-23.10 & \\
\hline
\end{tabular}

Abbreviations: $\mathrm{Cl}$, confidence interval; SD, standard deviation.

andependent $t$-test $(p<0.05)$.

${ }^{\mathrm{b}}$ Data of both patients and caregivers of dependent patients.

Table 3 Comparison among the subgroups (patient and caregivers) of both control and experiment group for medication compliance $(n=100)$

\begin{tabular}{|c|c|c|c|c|c|}
\hline \multirow[t]{2}{*}{ Patients $(n=100)$} & \multicolumn{3}{|l|}{ Posttest 1} & \multicolumn{2}{|l|}{ Posttest 2} \\
\hline & Groups (n) & Mean \pm SD & $p$-Value ${ }^{a}$ & Mean \pm SD & $p$-Value ${ }^{a}$ \\
\hline \multirow[t]{2}{*}{ Patient $(n=59)$} & Control (31) & $21.29 \pm 1.5$ & \multirow[t]{2}{*}{0.01} & $22.9 \pm 4.9$ & \multirow[t]{2}{*}{0.018} \\
\hline & Experimental (28) & $19.50 \pm 3.6$ & & $20.8 \pm 3.8$ & \\
\hline \multirow[t]{2}{*}{ Caregiver $(n=41)$} & Control (19) & $22.01 \pm 5.5$ & \multirow[t]{2}{*}{0.10} & $23.4 \pm 5.7$ & \multirow[t]{2}{*}{0.15} \\
\hline & Experimental (22) & $20.2 \pm 5.4$ & & $22.0 \pm 3.8$ & \\
\hline
\end{tabular}

Abbreviation: SD, standard deviation.

andependent $t$-test $(p<0.05)$.

perform ROM exercises as compared with the caregiver subgroup in both posttest assessments $(p=0.005$ and 0.001 , respectively). No significant difference was reported in level of confidence among caregivers of both study groups ( $p=0.9$ and 0.4 ) in posttests 1 and 2, respectively (-Table 4).

The overall level of confidence to perform deep breathing exercise (DBE) among experimental group was higher than that of control group with significant difference $(p=$ 0.003 and 0.004 ) in both posttests 1 and 2, respectively. On subgroup analysis, it showed that patients of experimental group reported moderate-to-high level of confidence in performing deep breathing exercises in posttests 1 and 2
( $p=0.001$ and 0.001 ) compared with patients of control group. In both posttests, there was no significant difference in level of confidence to perform DBEs as reported by caregivers of both control and experimental groups ( - Table 4 ).

The experimental group showed a moderate-to-high level of confidence for dietary changes as compared with control group ( $p=0.001$ and 0.001 ) in both posttests 1 and 2, respectively. The subgroup analysis showed that the patients of experimental group had moderate-to-high level of confidence for incorporating dietary modification as compared with patients of control group ( $p=0.001$ and 0.001$)$ in both visits, respectively ( - Table 4 ). 
Table 4 Subgroup analysis for comparing level of confidence for lifestyle modifications

\begin{tabular}{|l|l|l|l|l|l|l|}
\hline \multicolumn{2}{|l|}{ Level of confidence $^{\mathrm{b}}(p$-Value) } \\
\hline Patients $(n=100)$ & $\begin{array}{l}\text { ROM } \\
\text { (posttest 1) }\end{array}$ & $\begin{array}{l}\text { ROM } \\
\text { (posttest 2) }\end{array}$ & $\begin{array}{l}\text { DBE } \\
\text { (posttest 1) }\end{array}$ & $\begin{array}{l}\text { DBE } \\
\text { (posttest 2) }\end{array}$ & $\begin{array}{l}\text { Dietary } \\
\text { changes } \\
\text { (posttest 1) }\end{array}$ & $\begin{array}{l}\text { Dietary } \\
\text { changes } \\
\text { (posttest 2) }\end{array}$ \\
\hline $\begin{array}{l}\text { Patients subgroup } \\
\text { Control }(n=31) \text { vs. } \\
\text { experimental }(n=28)\end{array}$ & 0.005 & 0.001 & 0.001 & 0.001 & 0.001 & 0.001 \\
\hline $\begin{array}{l}\text { Caregivers subgroup } \\
\text { Control }(n=19) \text { vs. } \\
\text { experimental }(n=22)\end{array}$ & 0.9 & 0.4 & 0.7 & 0.5 & 0.004 & 0.001 \\
\hline
\end{tabular}

Abbreviations: DBE, deep breathing exercise; ROM, range of motion.

aFisher's exact test $(p<0.05)$

${ }^{\mathrm{b} N o}$ confidence, slight confidence, moderate confidence, and high confidence.

\section{Revisits Due to Complications}

Out of 100 , a total of 27 patients revisited hospital with complications after discharge of which $32 \%$ patients were in control group and $22 \%$ patients in experimental group, and there was no significant difference $(p=0.26)$ among

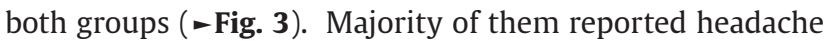
(6.12 and $5.10 \%$ ) followed by fever (5.10 and 4.8\%) among control and experimental groups.

\section{Satisfaction}

When compared the control and experimental groups, there was no significant difference in the satisfaction level with routine paper-based discharge summary in the first visit, where as in the second visit, the patients in experimental group were dissatisfied with paper-based discharge summary than the patients in control group ( $p=0.026$ ).

The patients in experimental group was strongly satisfied with the mobile app-based discharge teaching than paper-based discharge teaching $(p=0.003)$.

Overall satisfaction on discharge teaching among control group with routine paper-based discharge teaching and experimental group with mobile app-based discharge teaching were compared. This showed that there was no significant difference among the study groups in posttest 1 , whereas in posttest 2 , the experimental group showed high level of satisfaction than control group $(p=0.001)$.

\section{Mobile app Usage}

According to the data updated by the patients in the mobile app, $66 \%$ patients used 40 to $60 \%$ of mobile Apps for first month which was reduced to $8 \%$ patients in the second month. Also, $22 \%$ patients in the first month and $82 \%$ patients in the second month used below $40 \%$ of mobile app according to the data updated by them. There was also a drastic reduction in the mobile app usage as per the data collected through the datasheet in the posttest 2 (-Fig. 4 ).

Twenty-two patients contacted nurse investigator using the teleconsultation feature of the app through complaint chat $\log$ or uploading images through mobile app for the medical-related queries. Six patients had queries related to drug and computed (CT) scans which was further discussed

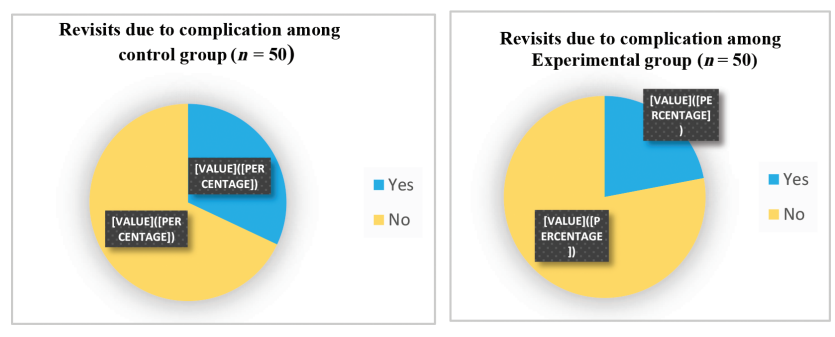

Fig. 3 Revisit to All India Institute of Medical Sciences due to complications after discharge $(n=100)$. Fisher's exact test $(p=0.26)$.

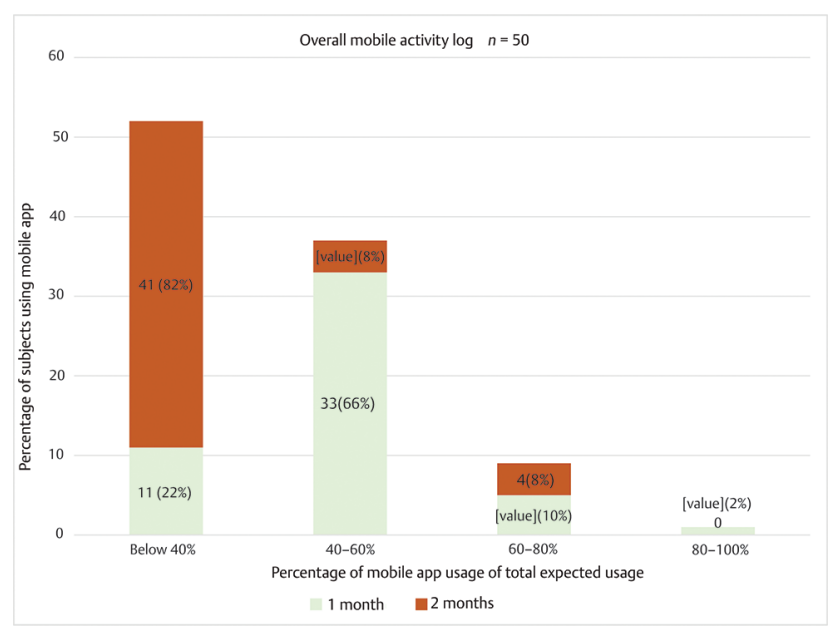

Fig. 4 Computerized record of mobile application usage.

with the concerned doctor and 28 patients had other queries related to future appointment date and technical issues.

\section{Discussion}

In the present study, the total mean score of medication compliance (as reported by patients or caregivers) among the control and experimental group showed no significant difference in posttests 1 and 2 ( $p=0.35$ and 0.53 ) which brings the fact that the intervention did not have much beneficial effect on medication compliance. Palmer et $\mathrm{al}^{4}{ }^{4}$ in their systematic review, reported that smart phone interventions did not have much beneficial effect on drug adherence. These results 
also support our findings which showed no significant effect among the control and experimental group.

The subgroup analysis showed that the patients of experimental group reported an improvement in medication compliance with total mean score of $19.50 \pm 3.6$ and $20.8 \pm 3.8$ (the lower the score, the better the compliance) both in posttests $1(p=0.01)$ and $2(p=0.018)$ than patients in control group with a score of $21.29 \pm 1.5(p=0.10)$ and $22.9 \pm 4.9$ $(p=0.15)$. The results of the subgroup analysis are consistent with the study done in Sweden by Johnston et $\mathrm{al}^{3}$ among cardiac patients. They reported that more drug adherence was seen among interventional group using support smart app than control group.

The level of confidence to perform ROM exercises showed no significant difference $(p=0.07)$ in the first posttest which was improved in the second posttest $(p=0.013)$ among experimental group. Our findings are consistent with the study findings by Safran Naimark et $\mathrm{al}^{5}$ where customized smart phone app and traditional instructions were used among 99 obese population for healthy lifestyle in terms of physical activity and diet. They reported that the there was a reduction in weight of $(1.44 \pm 0.4$ [standard deviation $(\mathrm{SD})]) \mathrm{kg}$ in the app group and $(0.128 \pm 0.36) \mathrm{kg}$ in the control group $(p=0.03)$.

In our study, the experiment group was more confident to adhere to the prescribed dietary practices than control group in both visits ( $p=0.001$ and 0.001 ). This can be well explained by the fact that experiment group had better information regarding the diet to be taken through the mobile app. Control group reported that specific dietary changes were not advised to them and were not concerned about the dietary modifications.

Our Study found that mobile app had no effect on revisits due to complications with no significant difference among the study patients $\left(p=0.36\right.$ ). Contrary to this, Felbaum et al, ${ }^{2}$ in their prospective study on 56 neurosurgical patients providing mobile app for reducing surgery cancellation, complications, and readmissions, reported no readmissions and only one event of complications among the study patients. This study was a prospective study with no controls and setting is different when compared with our study.

When compared the routine paper-based discharge teaching with mobile app-based discharge teaching within the experimental group, $18 \%$ reported strongly satisfied with mobile app-based discharge teaching $(p=0.003)$. The overall satisfaction with discharge teaching was reported to be more among experimental group when compared with control group $(p=0.001)$. Our findings are consistent with the findings of Safran Naimark et $\mathrm{al}^{5}$ who reported that users' satisfaction with the app was high (93\%).

In our study during the first month after discharge, computerized $\log$ report showed that $22 \%$ of participants used $<40 \%$ of use of mobile app, $66 \%$ of participants used 40 to $60 \%, 10 \%$ participants used 60 to $80 \%$, and $2 \%$ participants used $80 \%$ of the expected monthly usage in mobile app. During second month, the mobile app usage was drastically reduced, that is, from 66 to $8 \%$, and $82 \%$ used below $40 \%$ of total use. Our findings are consistent with other studies. Naimark et $a l^{5}$ reported a declining trend in use of mobile app over the study period from 7.8 to 14 weeks. The frequency of app use reduced over time and $27 \%$ users were still active on app out of 99 participants. The reduction in app usage may be due to the fact that the improvement in patient condition tends to be less serious on care.

\section{Implications}

Nurses can be empowered to have an outreach practice for home-based care using the innovative technology from the parent hospital, and thereby reinforcing homecare and health practices, resolving nursing-related queries, and thus reducing unplanned revisits to the hospital. Tele nursing can be incorporated in the outpatient department nursing service for regular monitoring and supporting the patients which will help in reducing the unplanned follow-up visits.

\section{Strength of the Study}

This is the first randomized controlled trial for assessing the effectiveness of nurse-driven mobile app based discharge teaching in India for the management of the home-based care of neurosurgical patients.

\section{Limitations}

The small sample size and the noncomparative nature of the analysis for certain variables limits our capacity to make conclusions with respect to clinical outcomes. Being a single-centered study, it limits generalizability of the study, and the study had a relatively shorter follow-up period.

The postinterventional data obtained from structured questionnaire was not complying with the computerized log obtained from mobile app since $40 \%$ patients updated the mobile app after discharge. This mismatch may be due to the subjectivity in the data collected which can influence the utility of different functions of mobile app.

\section{Conclusion}

Nurse-driven discharge teaching using Mobile app is an effective method for neurosurgical patients to adhere with the home-based health teachings.

Use of mobile app-based discharge teaching has shown improvement in various aspects of patient care like lifestyle practices (TT catheter care, exercises, and dietary changes) and satisfaction among the experimental group. However, medication compliance did not show any significant difference among the both groups. Subgroup analysis shows that the patient group reported more adherence for their self-care at home after discharge through mobile app when compared with caregivers. This can be probably because patients are more concerned and encouraged for their own care, but caregivers are just supplementing their patients' care. Exact cause for the same is not known. The overall satisfaction with discharge teaching was reported to 
be more among experimental group when compared with control group.

Use of technology like mobile apps in vernacular language can bridge the gap for improving home-based care and follow-up among patients in resource constrained settings.

\section{Recommendations}

A large-scale study with larger sample size in multiple hospital settings can be conducted for a longer duration. Further research can be conducted to assess the effectiveness of mobile app using video teleconsultation for patients from remote areas. Studies using technology acceptance model (TAM) can be conducted to explore user acceptance, intent to use, and user behavior of patient portal among neurosurgical patients.

\section{Ethical Approval}

This article received its Ethical permission from Institute Ethics Committee, All India Institute of Medical Sciences, New Delhi, and the study was registered in Clinical trials registry of India (CTRI/2019/10/021498).

\section{Conflict of Interest}

None declared.

\section{References}

1 Moghavem N, Morrison D, Ratliff JK, Hernandez-Boussard T. Cranial neurosurgical 30-day readmissions by clinical indication. J Neurosurg 2015;123(1):189-197

2 Felbaum DR, Stewart JJ, Anaizi AN, Sandhu FA, Nair MN, Voyadzis J-M. Implementation and evaluation of a smartphone application for the perioperative care of neurosurgery patients at an academic medical center: implications for patient satisfaction, surgery cancelations, and readmissions. Oper Neurosurg (Hagerstown) 2018;14(3):303-311

3 Johnston N, Bodegard J, Jerström S, et al. Effects of interactive patient smartphone support app on drug adherence and lifestyle changes in myocardial infarction patients: a randomized study. Am Heart J 2016;178:85-94

4 Palmer MJ, Barnard S, Perel P, Free C. Mobile phone-based interventions for improving adherence to medication prescribed for the primary prevention of cardiovascular disease in adults. Cochrane Database Syst Rev 2018;6(6):CD012675

5 Safran Naimark J, Madar Z, Shahar DR. The impact of a web-based app (eBalance) in promoting healthy lifestyles: randomized controlled trial. J Med Internet Res 2015;17(3):e56 